\section{On analog movements of visual attention}

\section{STEVEN YANTIS \\ Johns Hopkins University, Baltimore, Maryland}

A great deal of evidence has accumulated over the last 20 years or so suggesting that decisions concerning the contents of a visual scene can be enhanced with the assistance of advance information about the spatial location or locations in the scene that are likely to contain taskrelevant information. For example, Eriksen and his colleagues have demonstrated that reaction time to identify a target letter in visual search is improved when a spatial cue is provided about $200 \mathrm{msec}$ before the onset of the search display (Colegate, Hoffman, \& Eriksen, 1973; Eriksen \& Hoffman, 1972, 1973, 1974). Eriksen and Hoffman (1972) suggested that the spatial extent of the enhancement is limited to about $1^{\circ}$ of visual angle (see also Eriksen \& St. James, 1986). Posner and his colleagues have also provided evidence that attention can be spatially directed in response to an appropriately timed cue. Reaction time in a dot-detection task is enhanced when the dot appears in an attended location and is slowed when it appears in an unattended location (e.g., Posner, 1980; Posner, Snyder, \& Davidson, 1980). Jonides (1981) demonstrated that the effectiveness of spatial cues in focusing attention varies with their location: Peripheral cues apparently capture attention automatically, whereas central cues require effortful allocation procedures. LaBerge (1983) and Downing and Pinker (1985) showed that when subjects focus attention on a restricted spatial location, reaction time to objects at unattended locations increases with their distance from the focus. There is also evidence that attention is more efficiently applied to objects that are physically proximal to one another (e.g., Hoffman \& Nelson, 1981; Kahneman \& Henik, 1981; Podgorny \& Shepard, 1983; Posner et al., 1980).

A quite natural heuristic for this body of results is that the application of spatial attention is analogous to shining a spotlight on the visual field. Objects that fall under the "spotlight of attention" can be identified or detected more rapidly than other objects. This sort of analogy has been advocated by many writers (e.g. , Broadbent, 1982, p. 271; Downing \& Pinker, 1985; Eriksen \& Hoffman, 1973; Eriksen \& St. James, 1986; Eriksen \& Yeh, 1985; LaBerge, 1983; Posner, 1980; Posner, Cohen, \& Rafal, 1982, p. 188; Posner et al., 1980, p. 172; Shulman, Remington, \& McLean, 1979; Tsal, 1983). ${ }^{\text {' Only a few }}$ theorists (e.g., Duncan, 1981) question the viability of the spotlight metaphor. Certainly the spotlight metaphor is held with varying degrees of concreteness and differ-

I would like to thank C. W. Eriksen, J. Jonides, M. Kaiser, K. Koh, A. Osman, and J. Palmer for comments on earlier versions of the manuscript. Correspondence should be sent to Steven Yantis, Department of Psychology, Johns Hopkins University, Baltimore, MD 21218. ent writers have had different specific properties in mind when referring to an attentional spotlight. However, the ubiquity of the analogy reflects its popularity. This is not surprising, since it is an intuitively appealing and parsimonious mechanism that appears to encompass many of the documented phenomena of selective attention in a straightforward manner.

Two main properties of attention as spotlight are implicit in the metaphor. The first is that attention is (or can be) limited in spatial extent. The evidence for this property is compelling (see the references cited above). The second property of a spotlight, which is often carried along with the first, is continuous or analog movement along surfaces. If attention is directed to a location in space, and a new location requires attention, then the attentional spotlight moves in such a way that intermediate spatial locations are traversed during the reallocation. Several investigators have explicitly embraced the movement property in their treatments (e.g., Posner, 1980; Posner et al., 1980; Remington \& Pierce, 1984; Shulman et al., 1979; Tsal, 1983). The purpose of this note is to critically review the two major sources of evidence for ana$\log$ movements of attention (Tsal, 1983; Shulman et al., 1979), and to argue that this evidence is tenuous at best.

The logic of Tsal's (1983) experiment rests on the notion that a spotlight of attention would have a constant velocity and therefore would take more time to move longer distances. If this is true, Tsal reasoned, then reaction time to discriminate an object at successively more distant cued locations should be maximally enhanced at successively later moments in time after an appropriate spatial cue is presented. The subjects in Tsal's experiments rapidly discriminated an $X$ from an $O$ presented $4^{\circ}, 8^{\circ}$, or $12^{\circ}$ in the right or left visual periphery. At various moments before the target letter appeared, a dot was flashed at the location that would contain the target. Subjects were to shift their attention (while maintaining fixation) to the cued location as rapidly as possible in anticipation of target presentation. Reaction time to targets in each location declined linearly to an asymptote. The asymptote was achieved at successively later moments in time after the cue appeared at the $4^{\circ}, 8^{\circ}$, and $12^{\circ}$ distances. Tsal took this as strong evidence that the spotlight of attention moves at a constant velocity over spatial locations.

Two problems with this conclusion are evident. First, the data are quite consistent with a model in which attention is reallocated abruptly, rather than continuously, from one location to another. According to such a model, attention is allocated to the cued location at some stochastically dependent moment in time after the cue appears. On trials in which the target appears before attention is reallocated, reaction time is slow. On trials in which the target appears after attention is reallocated, reaction time is fast. Overall reaction time will be a mixture of slow and 
fast trials. As the cuing interval increases, the proportion of trials on which reaction time is fast increases, proportionately increasing the mean reaction time in that condition. Differences in the moment at which asymptote was achieved in Tsal's (1983) experiment for the three eccentricities (and hence differences in the moment at which the discrete reallocation of attention occurred) is accounted for under this model by the differences in the time to perceive the cues at each location (Tsal's control experiment notwithstanding). Tsal's data cannot discriminate this discrete model from the one he asserts his data support.

The second difficulty with Tsal's (1983) conclusion concerns the interpretation of his time-course data. As several investigators have shown (e.g., Bertelson, 1967; Colegate et al., 1973; Eriksen \& Hoffman, 1974; Posner \& Boies, 1971; Posner et al., 1980), when a warning signal of any kind precedes a display, general arousal or alertness effects frequently arise that are quite independent of whatever specific effects (spatial or otherwise) accompany the cue. Such effects can sometimes be estimated by the inclusion of a "neutral" cue that produces only general alertness effects, and no specific effects. Tsal did not include a neutral condition.

Remington and Pierce (1984) provided data that speak to this point. Their subjects detected the onset of a dot occurring $2^{\circ}$ or $10^{\circ}$ to the right or left of fixation. In Experiment 1 , the side likely to contain the target dot was cued by an arrow preceding target onset by 16-600 msec. Experiment 2 was the same except that the stimulus-onset asynchronies (SOAs) were slightly different (50-550 msec) and one-third of the cues were spatially neutral crosses. In both experiments, Remington and Pierce found pronounced effects of cue-target SOA on reaction time under the informative cues, as did Tsal (1983). However, they also found such effects under the neutral cues of Experiment 2 . Remington and Pierce concluded, while taking the general alerting effect into account, that asymptotic benefits of the cue occurred at constant moments in time after cue onset, regardless of distance.

What is important for present purposes is that reaction times under valid cues cannot be sensibly interpreted without reference to the time-course function observed under the neutral cues. To assume that the SOA effects produced by valid cues are due only to spatial shifts of attention is simply inappropriate. Tsal's failure to evaluate the general alerting effects of his cues makes interpretation of his time-course functions difficult at best. Certainly his assumption that there were no general alerting effects is questionable.

A second study in support of an analog attentional mechanism has also been quite influential. Shulman et al. (1979) tested the following prediction of the analog movement hypothesis: A spotlight, as it moves from point $\mathbf{A}$ to point $\mathrm{B}$, must traverse (and thereby illuminate) every intermediate point before B is reached. Thus, if visual attention is accurately described as moving in an analog fashion, like a spotlight, evidence of its application at points between the starting and destination locations should be observed.

Subjects in the Shulman et al. (1979) study pressed a single key at the onset of a target light in one of four positions $\left(8^{\circ}\right.$ or $18^{\circ}$ to the right or left of fixation). On each trial, an arrow pointing to the right or left indicated that the far light on the indicated side was likely to be the target. The expected position was illuminated on $70 \%$ of the trials on which a light appeared, and each of the other three positions was illuminated on $10 \%$ of the trials. The cue arrow appeared 50-500 msec before the onset of the target light. Eye position was monitored to ensure continuous fixation. The $18^{\circ}$ position on the cued side, which had a $70 \%$ chance of being illuminated, was referred to as the far expected position. Similarly, the other three positions were referred to as the near expected, near unexpected, and far unexpected positions.

According to Shulman et al. (1979), the analog movement hypothesis predicts that performance on trials in which the target appears in the near expected position should improve and then decline relative to performance on trials in which the target appears at the far expected position. According to the hypothesis, the attention spotlight will move from fixation at cue onset continuously out toward the far expected position, necessarily passing over the near expected position as it moves. Because the near expected position is nearer the fovea, where acuity is better, performance is expected to be better overall there; what is crucial, however, is the improvement and then decline in performance at the near expected position relative to performance at the far expected position. The measure of interest, then, is near expected RT subtracted from far expected RT as a function of SOA; this function should be single-peaked, so long as target eccentricity and spotlight velocity are encompassed by the range of chosen SOAs.

\section{Models}

In order to interpret the results of Shulman et al.'s (1979) experiment, we must specify how the attentional spotlight affects behavior. There are at least three models of the dynamics of an analog attentional spotlight.

Model 1. We may assume that the attention spotlight must be directed at the location occupied by the target event before that event can be detected. This would require that reaction time be prolonged by the time taken to move attention to the target event. This model is quite implausible, of course, inasmuch as it begs the question of how the target is detected when the target occupies an unexpected location or when there are no cues.

Model 2. We can assume that the spotlight of attention enhances the extraction of information at the location to which it is directed, but that otherwise it has no effect on performance. This is a spotlight with a sharp focus. When the spotlight happens to fall on a target event, reaction times will be faster than on trials when attention is directed elsewhere. At long SOAs, the spotlight is more 
likely to have achieved the target location by the time the target appears there, and therefore is more likely to enhance reaction times, thus leading to an SOA effect.

Model 3. We can generalize Model 2 by adding a gradient around the current focus of attention, analogous to the penumbra of a physical spotlight. This is apparently the model Shulman et al. (1979) had in mind when they asserted that "reaction time tends to be a direct function of the distance of the target light from the present focus of attention" (p. 525, Footnote 1), although they provided no data to back this claim. This model allows for attenuated enhancement of targets falling in the penumbra of attention, with the magnitude of attenuation perhaps changing dynamically with time.

I now evaluate the analog movement hypothesis, as instantiated in these models, in light of the results of Shulman et al. (1979). In that experiment, the difference in reaction time between the near expected and the far expected positions did exhibit an increase and then a decrease with SOA. This finding is consistent with all three models outlined above, and Shulman et al. concluded that the analog movement hypothesis was supported. However, several difficulties with this conclusion arise when other aspects of the data are examined.

The data reveal that latencies to targets occupying the near unexpected and the far expected positions were nearly identical for SOAs of up to $350 \mathrm{msec}$ (all differences were less than $8 \mathrm{msec}$ ). Yet according to the hypothesis, the current focus of attention during this period moved more than $8^{\circ}$ closer to the far expected position and more than $8^{\circ}$ farther from the near unexpected position. This is not consistent with Model 1, which predicts that reaction times to targets in the near unexpected position should increase relative to those in the far expected position as SOA increases, due to the relative differences in the amount of time needed to move the attentional spotlight to the target location.

According to Model 2, latencies to a target in the near expected position ought to be very similar to those for the near unexpected position when the spotlight is not traversing the near expected locaticn. This presumably is the case when there is a relative convergence between the near expected and far expected functions. This prediction was not supported by the data, however; latencies to targets on the expected side were always faster than to those on the unexpected side, even when retinal eccentricity was held constant. The spotlight hypothesis therefore also fails under Model 2.

Finally, according to Model 3, a gradual improvement in responses to targets occupying the positions the spotlight is approaching should be observed, along with a relative decline in responses to targets occupying the positions the spotlight is moving away from. The data also fail to support this model, since the latencies to the near unexpected target (from which attention is being withdrawn) and the far expected target (toward which atten- tion is moving) are nearly identical to an SOA of $350 \mathrm{msec}$, as noted above.

Although some of Shulman et al.'s (1979) results are consistent with the predictions of the analog movement hypothesis, other aspects of the results (particularly those associated with responses to targets on the unexpected side) are inconsistent with equally important predictions of the hypothesis. The pattern of results from Shulman et al.'s experiment are complex and interesting; however, they cannot be accounted for by a simple mechanism involving analog movements of an attentional spotlight.

\section{Summary}

The conclusions of Tsal (1983) and of Shulman et al. (1979) concerning the dynamics of attentional shifts can be questioned on several counts. Tsal's data are confounded with generalized alertness effects, and therefore cannot be accounted for by appealing only to the movement of an attentional spotlight. Shulman et al.'s data are ambiguous with respect to the analog movement hypothesis. Models of visual attention allocation that postulate an attentional spotlight mechanism that moves continuously across surfaces are neither supported nor disconfirmed by these results. Instead, Tsal's and Shulman et al.'s data are simply inconclusive about whether attention shifts have continuous or discrete dynamics.

Vroon (1987) has pointed out that "metaphors are neither right nor wrong; they are more or less fruitful. Theories disappear when their predictions turn out to be false; metaphors disappear because a new one promises to answer more questions" (p. 398). We must keep in mind that the idea of an "attentional spotlight" is not a theory, but a heuristic metaphor. Until a better metaphor is advanced, this one will probably remain with us. Nevertheless, it remains to be seen how fruitful it will be in furthering attentional theory.

\section{REFERENCES}

BERTELSON, P. (1967). The time course of preparation. Quarterly Journal of Experimental Psychology, 19, 272-279.

BroAdBENT, D. E. (1982). Task combination and the selective intake of information. Acta Psychologica, 50, 253-290.

Colegate, R., Hoffman, J. E., \& Eriksen, C. W. (1973). Selective encoding from multielement visual displays. Perception \& Psychophysics, 14, 217-224.

Downing, C. J., \& Pinker, S. (1985). The spatial structure of visual attention. In M. Posner \& O. Marin (Eds.), Attention and Performance $X I$ (pp. 171-187). Hillsdale, NJ: Erlbaum.

Duncan, J. (1981). Directing attention in the visual field. Perception \& Psychophysics, 30, 90-93.

Eriksen, C. W., \& HoffMan, J. E. (1972). Temporal and spatial characteristics of selective encoding from visual displays. Perception \& Psychophysics, 12, 201-204.

ErIKSEN, C. W., \& Hoffman, J. E. (1973). The extent of processing of noise elements during selective encoding from visual displays. Perception \& Psychophysics, 14, 155-160.

Eriksen, C. W., \& Hoffman, J. E. (1974). Selective attention: Noise suppression or signal enhancement? Bulletin of the Psychonomic Society, 4, 587-589. 
ERIKSEN, C. W., \& Sr. JAmES, J. D. (1986). Visual attention within and around the field of focal attention: A zoom lens model. Perception \& Psychophysics, 40, 225-240.

ERIKSEN, C. W., \& YEH, Y. (1985). Allocation of attention in the visual field. Joumal of Experimental Psychology: Human Perception \& Performance, 11, 583-597.

Hoffman, J. E., \& Nelson, B. (1981). Spatial selectivity in visual search. Perception \& Psychophysics, 30, 283-290.

JONIDES, J. (1981). Voluntary vs. automatic control over the mind's eye's movement. In J. B. Long \& A. D. Baddeley (Eds.), Attention and Performance IX (pp. 187-203). Hillsdale, NJ: Erlbaum.

Kahneman, D., \& Henik, A. (1981). Perceptual organization and attention. In M. Kubovy \& J. R. Pomerantz (Eds.), Perceptual organization (pp. 181-211). Hillsdale, NJ: Erlbaum.

LABERGE, D. (1983). Spatial extent of attention to letters and words. Journal of Experimental Psychology: Human Perception \& Performance, 9, 371-379.

Podgorny, P., \& SHEPard, R. N. (1983). Distribution of visual attention over space. Journal of Experimental Psychology: Human Perception \& Performance, 9, 380-393.

PosNer, M. I. (1980). Orienting of attention. Quarterly Journal of Experimental Psychology, 32, 3-25.

Posner, M. I., \& BoIEs, S. J. (1971). Components of attention. Psychological Review, 78, 391-408.

Posner, M. I., Cohen, Y., \& Rafal, R. D. (1982). Neural systems control of spatial orienting. Philosophical Transactions of the Royal Society of London, B 298, 187-198.
Posner, M. I., Snyder, C. R. R., \& Davidson, B. J. (1980). Attention and the detection of signals. Journal of Experimental Psychology: General, 109, 160-174.

Remington, R., \& Pierce, L. (1984). Moving attention: Evidence for time-invariant shifts of visual selective attention. Perception \& Psychophysics, 35, 393-399.

Shulman, G. L., Remington, R., \& Mclean, J. P. (1979). Moving attention through visual space. Journal of Experimental Psychology: Human Perception \& Performance, 5, 522-526.

TsaL, Y. (1983). Movements of attention across the visual field. Journal of Experimental Psychology: Human Perception \& Performance, 9, 523-530.

VROON, P. A. (1987). Man-machine analogs and theoretical mainstreams in psychology. In W. J. Baker, M. E. Hyland, H. Van Rappard, \& A. W. Staats (Eds.), Current issues in theoretical psychology (pp. 393414). Amsterdam: North-Holland.

\section{NOTE}

1. Eriksen and St. James (1986) suggested a "zoom lens" model that emphasizes the variable size of the region of the display that is enhanced, rather than its movement properties. In some ways, this analogy is preferable to the "spotlight" analogy because of this difference in emphasis.

(Manuscript received June 5, 1987; revision accepted for publication August 10, 1987.) 